\title{
Ortotanásia: uma decisão frente à terminalidade
}

Kilda Mara Sanchez y Sanches ${ }^{1 \text { th }}$

Eliane Maria Fleury Seidl2

SANCHEZ Y SANCHES, K.M.; SEIDL, E.M.F. Orthothanasia: a decision upon facing terminality. Interface - Comunic., Saude, Educ., v.17, n.44, p.23-34, jan./mar. 2013.

Orthothanasia is regulated in Brazil through Resolution 1805/2006. This study aimed to reflect on and discuss the practices of limitation or withdrawal of life support in situations of terminality, using contributions from bioethics. Ten oncologists working in the Federal District's public health service participated. A semi-structured interview framework directed the themes to be investigated. The data were assessed by means of content analysis. Almost all of the participants had a conception of orthothanasia and euthanasia compatible with the literature. Seven doctors knew the FCM Resolution and three mentioned the legal weakness of a regulation originating from a professional body. Eight doctors said that the regulation of the issue would not greatly affect their daily practice. Bioethical principles like autonomy, beneficence, non-harmfulness and justice may contribute towards elucidation of dilemmas regarding removal or limitation of life.

Keywords: Death. Terminality. Orthothanasia. Life support. Bioethics.
A ortotanásia está regulamentada no Brasil pela Resolução 1805/2006. A pesquisa objetivou refletir e discutir, com contribuições da bioética, sobre práticas de limitação ou retirada de suporte vital em situações de terminalidade. Participaram dez médicos oncologistas de serviços públicos de saúde do Distrito Federal. Um roteiro de entrevista semiestruturada norteou os eixos temáticos investigados. Os dados foram analisados por meio de análise de conteúdo. A quase totalidade dos participantes tinha uma concepção de ortotanásia e de eutanásia compatível com a literatura. Sete médicos conheciam a resolução do CFM e três mencionaram a fragilidade legal de uma regulamentação proveniente de uma entidade de classe. Oito médicos afirmaram que essa regulamentação não afetará sobremaneira a prática cotidiana. Princípios bioéticos, como autonomia, beneficência, não-maleficência e justiça, podem contribuir para a elucidação de dilemas sobre a retirada ou limitação de suporte vital.

Palavras-chave: Morte. Terminalidade. Ortotanásia. Suporte vital. Bioética.

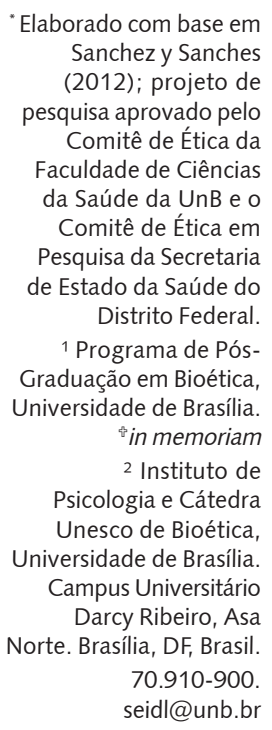

Elaborado com base em Sanchez y Sanches (2012); projeto de pesquisa aprovado pelo Comitê de Ética da Faculdade de Ciências da Saúde da UnB e o Comitê de Ética em Pesquisa da Secretaria de Estado da Saúde do Distrito Federal.

1 Programa de PósGraduação em Bioética, Universidade de Brasília. in memoriam 2 Instituto de

Psicologia e Cátedra Unesco de Bioética, Universidade de Brasília. Campus Universitário Darcy Ribeiro, Asa Norte. Brasília, DF, Brasil. 70.910-900. seidl@unb.br 


\section{Introdução}

No mundo moderno, o homem vem se empenhando em encontrar, por meio da ciência e da tecnologia, formas de vencer ou adiar a morte (Pessini, 2004). De fato, o prolongamento da vida tem se tornado cada dia mais sofisticado e tecnológico (Pelizzolli, 2007; Gracia, 1999). Em vista disso, a morte tem se transformado em um momento muitas vezes solitário e embaraçoso, quando a pessoa em condição de terminalidade, que precisa de cuidados médico-hospitalares, é retirada de seu convívio familiar e afastada das relações interpessoais, o que costuma ser bem frequente já que estar no hospital pode representar a obtenção de todos os cuidados necessários (Siqueira, Zoboli, Kipper, 2008; Pessini, 2004).

Um paciente sob cuidados paliativos é aquele cujos recursos conhecidos para a cura da doença esgotaram-se (Silva, Hortale, 2006; Girond, Waterkempe, 2006; Pessini, Bertachini, 2004). O direito de morrer com dignidade significa que as pessoas podem viver os últimos dias de suas vidas cercadas de amor e carinho e que não estão desamparadas nessa fase de transição entre a vida e a morte. Os cuidados paliativos devem garantir que essas pessoas possam decidir sobre o seu tratamento, incluindo o direito de escolher onde morrer e como morrer, o alívio da dor e do sofrimento inútil. Ou seja, é dar ao paciente incurável a possibilidade de morrer com nobreza e integridade, com respeito por sua autonomia e dignidade (Migliore et al., 2010).

Ortotanásia é o não-investimento de ações obstinadas, e mesmo fúteis, que visam postergar a morte de um indivíduo cuja doença de base insiste em avançar acarretando a falência progressiva das funções vitais. Na medida em que recursos terapêuticos não conseguem mais restaurar a saúde, as tentativas técnicas tornam-se uma futilidade ao intensificarem esforços para manter a vida. Trata-se, portanto, de um conceito relacionado aos cuidados paliativos (Reiriz et al., 2006; Pessini, Bertachini, 2004), ou seja, cuidados dispensados à pessoa cuja doença não tem possibilidades de cura.

Já o ato cometido ou omitido para provocar ou acelerar a morte de alguém é denominado eutanásia. Existem algumas especificidades que caracterizam os dois tipos de eutanásia. A eutanásia ativa consiste na realização de algum procedimento que culmine na morte. Na eutanásia passiva, a omissão de algum procedimento provoca o óbito. É importante ressaltar, também, a diferença entre ortotanásia e eutanásia passiva, conceitos que são frequentemente confundidos. Na ortotanásia, é a doença de base a responsável pela morte; na eutanásia passiva, a moléstia não é fatal, ou ainda não chegou ao ponto da terminalidade, da reta final da vida. A eutanásia passiva abrevia a vida e a ortotanásia permite a morte (Menezes, Selli, Alves, 2009).

Distanásia é aquela tentativa de combater a morte a qualquer custo, prolongando um sofrimento e agonia desnecessários. A distanásia nega o princípio da não-maleficência, por isso pode-se dizer que é uma deformidade da conduta médica. O tratamento fútil deveria dar lugar aos cuidados paliativos que se pautam na humanização e na qualidade de vida e de morte (Menezes, Selli, Alves, 2009).

Para auxiliar os médicos quanto a decisões a serem tomadas em face de doenças crônicas incuráveis, o Conselho Federal de Medicina (CFM) editou a Resolução 1.805/06 (Conselho Federal de Medicina, 2006) que autoriza médicos a limitarem ou suspenderem procedimentos e tratamentos que prolonguem a vida do doente em fase terminal, de enfermidade grave e incurável, respeitada a vontade da pessoa ou de seu representante legal. Esse documento deverá ter repercussões relevantes nas práticas profissionais em contextos de terminalidade e do fim da vida.

A Resolução 1.805 chegou a ser suspensa pois, segundo o Ministério Público (MP), o CFM não tem competência para legislar sobre matéria do Código Penal. No entendimento do MP, a suspensão ou limitação de tratamento seria um abreviamento da vida, característico da eutanásia passiva. Em 2010, o impedimento do MP em relação à prática da ortotanásia foi considerado improcedente pela $14^{\mathrm{a}}$ Vara Federal, ao argumentar que o CFM tem competência para editar uma norma com esse teor, que não versa sobre direito penal, mas, sim, sobre ética médica e consequências disciplinares. Há iniciativas, no entanto, visando dar a essa regulamentação força de lei. Com o texto substitutivo aprovado, um projeto de lei que regulamenta a ortotanásia já tramita no Congresso Nacional, sob o número 6.715/09, pretendendo remover, do Código Penal, a proibição quanto à limitação de tratamento para pacientes sem possibilidades de cura. 
Esses temas têm sido objeto de pesquisas empíricas, com o propósito de investigá-los a partir da ótica de profissionais de saúde. Vasconcelos, Imamura e Villar (2011) investigaram o impacto da Resolução 1.805/06 do CFM sobre 83 médicos que lidavam regularmente com a morte. Os autores observaram que, entre os conceitos de ortotanásia, distanásia e eutanásia, o de ortotanásia gerou maior confusão conceitual. Pouco mais da metade dos participantes $(55,4 \%)$ se mostrou favorável à prática da eutanásia, e 80,7\% foram contrários à distanásia. Por outro lado, 56\% deles, que afirmaram desconhecer a Resolução 1.805 do CFM, admitiram praticá-la no cotidiano, após tomarem conhecimento do seu conteúdo no contexto da pesquisa. A conclusão do estudo apontou que o conhecimento da Resolução afetou positivamente a rotina dos entrevistados, que referiram atuar com base em valores mais humanitários.

Outro estudo que investigou efeitos da Resolução 1.805/06 (Vane, Posso, 2011) sobre cem médicos que trabalhavam em UTIs em São Paulo constatou que $49 \%$ deles desconheciam a Resolução. Foi elevado o consenso, entre os entrevistados, acerca de que o médico tem a obrigação de esclarecer o paciente ou seu representante legal sobre as modalidades terapêuticas adequadas para cada situação; e que o paciente deverá receber todos os cuidados necessários para aliviar os sintomas que levam ao sofrimento, sendo assegurada a assistência integral, o conforto físico, psíquico, social e espiritual, inclusive o direito da alta hospitalar, para morrer junto a seus familiares.

Uma pesquisa realizada em Curitiba (Urban et al., 2008) com 31 oncologistas verificou que $74,2 \%$ deles eram favoráveis à participação dos pacientes nas decisões envolvendo o final da vida, e 80,6\% manifestaram-se contra o direito da família de decidir sobre a abreviação da vida do paciente. A conclusão dos autores foi que temas dessa natureza continuam sendo objeto de intensos debates bioéticos, e a humanização dos cuidados no final da vida deve ser priorizada na formação médica.

Em estudo feito no Distrito Federal (Batista, Seidl, 2011), que contou com a participação de quinze médicos intensivistas procedentes do estado de Goiás e do Distrito Federal, constatou-se que $60 \%$ dos participantes conheciam a Resolução 1.805/06. Também foi observada confusão entre os termos eutanásia e ortotanásia, o que levou a autora a alertar para a necessidade de se difundirem esses conceitos para aqueles que lidam com a morte em seu cotidiano profissional. Os relatos indicaram ainda que a irreversibilidade do quadro clínico e o prognóstico da doença foram os fatores que mais nortearam a decisão quanto à limitação ou retirada de suporte vital para os médicos que participaram do estudo. A importância do papel da família no processo decisório também foi enfatizado pelos participantes.

Médicos, enfermeiros, outros profissionais de saúde e bioeticistas estão interligados por um propósito ético e moral comum, e precisam ser norteados por uma fonte compartilhada de moralidade, com regras fundamentais, princípios e virtudes que definirão uma vida moral consistente com os propósitos das ciências da saúde (Marino Junior, 2009). Torna-se imprescindível discutir mais, e detalhadamente, os princípios éticos, pois neles se devem basear as decisões a tomar. Assim, a autonomia deve ser suscitada, protegida, reforçada e respeitada, devendo ser evitada qualquer pressão ou imposição sobre o paciente e familiares. A beneficência é um ato de bondade ou gentileza, uma atuação benevolente, segundo o interesse maior do paciente. Neste sentido, a ortotanásia pode ser considerada como gesto regido pela beneficência. A não-maleficência atua no sentido da prevenção e remoção de situações prejudiciais, o que pode ser perfeitamente associado à ortotanásia. A justiça dá a cada um o que necessita e tem direito. Nessa perspectiva, o paciente em condição de terminalidade tem direito a cuidados paliativos que incluem, na sua essência, a busca intensiva pela melhoria da qualidade de vida e promoção de conforto, conseguido através do alívio da dor em sua totalidade (Moritz, 2009).

O objetivo geral da presente pesquisa foi refletir e discutir, com contribuições da bioética, sobre práticas de limitação ou retirada de suporte vital em situação de terminalidade, a partir de relatos de médicos oncologistas. Os objetivos específicos foram: conhecer as concepções dos participantes sobre ortotanásia e eutanásia; identificar as influências que norteiam a tomada de decisão quanto à limitação ou retirada de suporte vital em situações de terminalidade, bem como fatores que interferem nessa decisão; investigar o conhecimento da Resolução 1.805/06 do CFM e seus efeitos sobre a prática médica em contextos de fim da vida, na percepção de médicos oncologistas.

Os oncologistas são profissionais da saúde que lidam frequentemente com o fim da vida, motivo pelo qual optou-se por incluí-los no estudo. A pesquisa se justifica pois as enfermidades crônicas 
crescem em prevalência, em especial o câncer, devido, sobretudo, aos avanços tecnológicos e à busca pelo prolongamento da vida. Assim, práticas como a da ortotanásia tendem a ser cada vez mais frequentes no enfrentamento de situações de terminalidade.

\section{Método}

\section{Participantes}

Dez médicos oncologistas de dois hospitais públicos do DF, sendo seis homens, com tempo de formação de nove anos em média. Os dez referiram realização de residência em oncologia clínica e um deles tinha curso de mestrado. Os entrevistados foram denominados de E1 a E10.

\section{Instrumento e procedimento de coleta de dados}

Foi utilizado um roteiro de entrevista semiestruturada com questões que permitiram a obtenção de relatos acerca de oito eixos temáticos de interesse: (1) concepção de ortotanásia e eutanásia; (2) influências na decisão acerca da limitação ou retirada de suporte vital em condição de terminalidade; (3) relação médico-paciente; (4) enfrentamento de conflitos entre profissionais e familiares em situações do fim da vida; (5) aplicação de limitação de suporte vital: quem toma a iniciativa de conversar sobre o assunto e decide fazer?; (6) contribuição da formação e da experiência profissional nas práticas de retirada ou limitação de suporte vital; (7) conhecimento da Resolução 1.805/2006 do CFM; (8) efeitos da Resolução 1.805/2006 na prática atual dos profissionais de medicina.

Após análise e aprovação do projeto por Comitê de Ética em Pesquisa, o estudo teve início. A pesquisadora principal entrevistou os médicos que aceitaram participar e assinaram o Termo de Consentimento Livre e Esclarecido (TCLE). Nenhuma recusa ocorreu entre os que foram convidados. A entrevista teve duração média de trinta minutos e foi realizada no local de trabalho de cada profissional, em condição de privacidade e conforto satisfatórios. As entrevistas foram gravadas em áudio para posterior transcrição e análise.

\section{Análise de dados}

Inicialmente, as entrevistas foram transcritas na íntegra; procedeu-se, então, a uma leitura flutuante do corpus. Os relatos verbais referentes aos oito eixos temáticos foram categorizados a partir de seu conteúdo (Bardin, 2009) por dois pesquisadores de modo independente (a pesquisadora e a orientadora), visando concordância igual ou superior a $70 \%$ para a identificação, nomeação e frequência das categorias. Efetuou-se, ainda, a seleção de trechos de relatos dos participantes como ilustração das categorias identificadas.

\section{Resultados}

Quanto à concepção de ortotanásia, a análise dos relatos permitiu compor três categorias: deixar a vida seguir seu curso; não realizar esforços fúteis; prover conforto e cuidados paliativos até o desfecho. Um participante não soube definir ortotanásia, tampouco eutanásia. Trechos das falas dos participantes contribuíram para delinear o conceito de ortotanásia, inseridos nas diferentes categorias identificadas. Assim, cada participante, em seu relato, aportou mais de um aspecto da conceituação de ortotanásia.

A categoria deixar a vida seguir seu curso teve cinco menções, sendo bem exemplificada pelo relato de E2: "ortotanásia é deixar a vida seguir o seu curso, só que ele (o paciente) tem qualidade e dignidade". A categoria não realizar esforços fúteis teve seis menções, e o relato de E8 fez uma boa explicitação: 


\begin{abstract}
"Na prática se constitui em uma parada de investimento em cima do paciente, entende? Não fazer nada milagroso. É diferente da eutanásia que interrompe a vida do paciente. A ortotanásia é deixar de fazer investimentos milagrosos no processo".
\end{abstract}

A categoria prover conforto e cuidados paliativos até o desfecho teve contribuições de cinco participantes, com trechos que a exemplificaram, como o relato de E4: "resta a gente dar cuidados paliativos, os cuidados básicos para que esse paciente viva sem sofrimento enquanto vida ele tiver".

O relato de $\mathrm{E} 9$ também é um exemplo dessa categoria:

"[...] É uma estratégia do médico que provê a capacidade de dar conforto e perceber que os instrumentos que ele tem não são mais eficazes para salvar aquela vida. Então não tentamos brigar com a morte, mas ficar a favor da vida".

Vale mencionar que um participante, E10, apontou a relação entre concepção de ortotanásia e valores pessoais: "[...] depende de uma série de coisas. De crença pessoal, de crença em Deus. Acompanhar a morte de uma pessoa sem induzi-la, eu acho que é o ideal".

Quanto à conceituação de eutanásia, três categorias foram identificadas: interrupção da vida; intervenção ativa do médico; indução da morte. A categoria interrupção da vida, com a contribuição de três relatos, pode ser ilustrada pela fala de E1: "Com a eutanásia você estaria mudando o curso da vida do paciente, interrompendo a vida dele. Com a ortotanásia, não".

No que tange à categoria intervenção ativa do médico, com quatro menções, esta pode ser exemplificada pelo relato de E6: "A eutanásia, eu entendo que é aquela forma de morrer que a medicina e o médico intervêm facilitando ou agilizando o processo de morte ou até programando a morte do paciente".

A terceira categoria, indução da morte, teve três menções, sendo ilustrada pela fala de E4: "você estaria fazendo com que uma situação acontecesse, você estaria induzindo o paciente ao óbito na eutanásia, seja por que motivo for, no caso seria o motivo de aliviar o sofrimento da pessoa". Outra fala que ilustra essa categoria é a de E9: "A eutanásia é quando você apressa a morte. Na ortotanásia você deixa morrer, é uma evolução natural [...]".

Concluiu-se que as categorias identificadas descrevem as concepções de ambos os conceitos e foram complementares no sentido de se obter uma definição pertinente e compatível com a literatura sobre ortotanásia e eutanásia.

No que tange às influências no processo de tomada de decisão para introdução ou não de suporte vital, os relatos permitiram identificar cinco categorias, indicando a diversidade de posição entre os participantes sobre essa questão: decisão é de todos; decisão é do médico; decisão é da família e do médico; decisão é do paciente e da família; decisão é da família. Dois entrevistados defenderam que a decisão é de todos, envolvendo médico, paciente e família, o que pode ser ilustrado pelo relato de E1:

"Acho que é uma decisão sempre muito difícil, tanto pra família quanto pro paciente e pro profissional de saúde [...] Mas o que eu vejo é que essa decisão tem que ser tomada em conjunto, principalmente quando o paciente está entendendo o que está acontecendo. E é uma decisão conjunta, não consigo ver isso de forma isolada".

Um profissional (E9) defendeu que a decisão é do médico, justificando que:

“Eu acho que é o aspecto do conhecimento técnico do profissional em relação àquela patologia. Quando você conhece a patologia e as várias opções terapêuticas, você sabe quando não tem mais nenhum recurso para utilizar. Os jovens têm mais dificuldade nesse aspecto, exige experiência". 
Outro participante (E4) ressaltou que a decisão envolve a família e o médico, conforme seu relato:

"[...] esse tipo de decisão não é só do médico. Essa decisão, de até onde ir, também tem que ser decidida com a família do paciente [...], as coisas devem ser muito bem conversadas, minha experiência pessoal é conversar e fazer o que puder fazer, mas quando eu perceber que eu estou passando do limite, eu sento e converso com a família".

Um profissional (E6) opinou que paciente e família norteiam essa decisão:

"Eu acho que a primeira situação é obedecer o paciente, ele tem que ser considerado. A segunda opção que também interfere muito, e acaba sendo a primeira, porque o paciente já não tem muita opção, é a questão da família [...] às vezes a gente tem que fazer uma intervenção mais agressiva e fazer algum procedimento a mais, e muitas vezes a gente faz por conta da família que é muito insegura, não entende, mesmo sendo explicado, tem dificuldade de aceitar que a gente não deve fazer mais coisas para o paciente e a gente é obrigado a fazer um procedimento de dar mais suporte de risco".

Um entrevistado (E7) afirmou que a posição da família tem influência predominante nessa decisão:

“Hoje em dia fazer ortotanásia no país ainda é algo ilegal, não temos respaldo legal pra isso. Então pra gente poder praticar a ortotanásia é necessária a anuência familiar. É preciso que a família compreenda o que está acontecendo e em que momento da doença está o paciente. O apoio familiar, a benção familiar, é fundamental para as atitudes que serão tomadas dali pra frente".

Quanto à influência da relação médico-paciente nas decisões do fim de vida, três participantes afirmaram que a relação deste binômio não só influencia como também auxilia a tomada de decisão. $O$ relato de E5 exemplifica a categoria:

"Influencia muito porque se não for uma relação bem estabelecida, fica extremamente difícil de traçarmos estratégia nesse sentido, não dá pra você tentar orientar nada nesse sentido, se você não tiver uma relação médico-paciente estruturada e bem estabelecida".

Três entrevistados referiram que a influência exercida é mais da relação do médico com a família, sendo salientada que a anuência familiar é um aspecto relevante, conforme discurso de E5:

"A participação da família é fundamental. Porque em determinado momento onde verdadeiramente a ortotanásia vai ser aplicada, o paciente não tem condições de tomar decisões por si só e nesse momento a família passa a ter um peso muito importante, ela tem que participar de todos os processos, todas as etapas da ortotanásia".

Outros três participantes salientaram a existência de um trinômio relacional formado por médico, paciente e família, elucidado por trecho da fala de E4:

"Chega-se a uma decisão ou com o paciente ou com a família. Temos uma cultura que não permite que se diga para o paciente toda a situação em que ele está, porque algumas pessoas pensam que o paciente que está terminal é aquele que está confuso ou em coma. Às vezes um paciente que está caminhando para um estado terminal está lúcido e ele tem condição de decidir alguma situação [...] temos uma dificuldade de chegar para o paciente terminal e realmente colocar a situação do jeito que ela é, e pedir até que ele decida também junto conosco o que é melhor para ele". 
Um participante, E8, rejeitou a ideia de influência dessas relações sobre a tomada de decisão, justificando que "[...] se influenciasse nunca faríamos isso. Nos apegamos muito aos pacientes, tomar uma decisão dessas é muito difícil tanto para a família quanto para o médico".

No que concerne à atitude do profissional em situações nas quais o paciente aceita a terminalidade e a família não, a maioria (seis participantes) afirmou que o desejo do paciente deve prevalecer, o que foi bem elucidado na resposta fornecida por E1:

"Eu costumo pedir pro paciente deixar por escrito o que ele deseja ou não. Mas a minha opinião pessoal é que a gente deve seguir o desejo do paciente. Na maioria das vezes a gente tenta ponderar com a família que o desejo do paciente é esse e tenta fazer com que a família de alguma forma aceite aquilo, mas sempre visando o desejo do paciente. Mas eu peço para que ele deixe por escrito até para me proteger do ponto de vista legal. Não é raro o paciente desejar uma situação, a família participar dessa decisão, mas no momento em que o paciente efetivamente tem uma insuficiência respiratória, ou alguma coisa que pode levar ao óbito iminente, a família voltar atrás e querer forçar o plantonista do hospital a realizar manobras mais invasivas".

Um entrevistado, E6, apontou que o desejo da família deve prevalecer, conforme trecho transcrito:

"Tentamos conversar com a família e com o paciente, o problema é que depois lidamos mais é com a família [...] depende do esclarecimento da família [...] porque é a família que fica com o paciente no final [...] Ficamos reféns da família."

Segundo oito participantes, as iniciativas no sentido de iniciar conversas sobre a aplicação de procedimentos de limitação ou retirada de suporte vital, de modo geral, partem do médico, mas, muitas vezes, com participação ou anuência do paciente. O relato de E7 é um bom exemplo dessa afirmativa:

"Acho que as coisas caminham muito juntas, fica difícil separar. Acho que todo mundo acaba pensando ao mesmo tempo, mas falta a coragem pra tomar a iniciativa. Normalmente a iniciativa é do médico. Mas a impressão que eu tenho é que toda vez que você conversa isso com o paciente e com a família eles acabam dizendo que já estavam percebendo que a coisa caminhava para esse rumo. Pode ser inclusive pelo fato de que a família não tem muito conhecimento a respeito disso, por medo de ser mal interpretada. Alguns têm receio de que, ao sugerir uma coisa dessas, pareça que não gostem do paciente. Então pra família isso é mais complexo. O paciente já tende a perceber mais a necessidade do procedimento, até por que é ele que está vivenciando a doença, sofrendo os sintomas [...]. Então acho que isso parte de vários locais, mas normalmente quem toma a iniciativa é o médico ou o paciente".

Um dos entrevistados afirmou que a iniciativa tende a partir da família do paciente, tal como na fala de E4: "O que eu observo é que na maioria das vezes a própria família chega e começa a conversar sobre quando parar, então parte deles a iniciativa de falar".

E1 apontou que o pedido costuma partir do próprio paciente, como o trecho a seguir ilustra:

“[...] é ele que está vivenciando. Ele sabe que a partir de determinado momento as coisas não vão caminhar bem, não vão ser boas pra ele. Mas a família tem mais dificuldade de entender isso, essa relação com os familiares é sempre um pouco mais difícil do que com o paciente".

Quanto a quem deve se envolver efetivamente na tomada de decisão sobre a ortotanásia, E9 afirmou que apenas o médico, conforme seu relato: 
“Prioritariamente o médico. O próprio nome já diz, paciente. Se o médico disser que ele vai fazer quimioterapia até a hora da morte ele não tem como discutir, não tem conhecimento técnico. Então a decisão é do médico, mas com base no desejo do paciente".

A metade dos entrevistados afirmou que todos devem se envolver nessa decisão, ilustrada pelo discurso de E1: "Acho que o paciente, os familiares e médico. Tem que ser uma decisão tomada em conjunto, mas o poder de decisão é sempre do paciente, ninguém tem mais voz do que ele".

Com respeito à contribuição do curso de graduação em medicina para a consolidação de atitudes frente à retirada ou limitação de suporte vital, sete médicos afirmaram que a formação foi deficiente nesse aspecto, sendo que os demais não explicitaram bem suas posições nesse tema. A fala de E7 exemplifica essa afirmativa, destacando a ênfase na teoria e a ausência de prática nos cursos:

“No currículo da faculdade de medicina em si não temos muita discussão sobre isso. Então não existe, por exemplo, uma disciplina que trate especificamente dessa questão da terminalidade. A gente acaba discutindo isso quando tem a oportunidade de ver pacientes de médicos que já tenham mais experiência nesse sentido, mas não há nada na nossa grade curricular que trate disso. Você acaba discutindo com colegas, lendo a respeito, indo a algum congresso que tenha algo específico dessa área".

Seis entrevistados disseram que tal contribuição surgiu efetivamente a partir das experiências profissionais desenvolvidas na residência médica. E2 afirmou que: "a formação que eu tive na residência, tinha um hospital que era só de cuidados paliativos, então eu tive muito contato com essa coisa de suporte".

Ao serem indagados sobre o conhecimento da Resolução 1.805/2006 do CFM, sete participantes responderam afirmativamente. O entrevistado E5 expressou as vantagens dessa regulamentação ao afirmar que: "cria um suporte legal pra indicação de um procedimento médico que é histórico dentro da medicina, mas que a gente não tinha um suporte legal para essa indicação".

Mas, dentre os sete médicos que responderam que conheciam o documento, três se mostraram preocupados com a fragilidade legal de uma regulamentação proveniente de uma entidade de classe. $\mathrm{O}$ relato de E7 foi o que melhor expressou tal situação:

"A proposta dela seria que nós, médicos, tivéssemos respaldo jurídico pra esse tipo de procedimento... Só que essa resolução foi cancelada sob a afirmação de que o CFM não tem poder de legislar a respeito de algo que é tido como crime. Então a resolução foi feita pra dar esse respaldo jurídico, mas não cumpria sua função. Ela é uma resolução bastante interessante $[\ldots]^{\prime \prime}$.

Três médicos afirmaram desconhecer a Resolução. Ainda nesse eixo temático, alguns entrevistados fizeram menção ao Código de Ética Médica no decorrer de suas falas, destacando que este não é suficiente para dar respaldo a decisões relativas ao fim da vida.

Entre os sujeitos da pesquisa, oito afirmaram que a regulamentação da questão não deverá afetar sobremaneira a rotina atual, pois conceitos morais e éticos tendem a nortear essas práticas. Um discurso foi selecionado para elucidar essa categoria:

"As leis vêm pra normatizar coisas que a sociedade já realiza. Se a sociedade vai contra a lei há algo de errado. Ou essa lei está muito severa ou ela não traduz corretamente o que a sociedade está pensando. [...]. Então, claro, tendo uma lei que ampara é muito mais fácil. Você não vira alvo de reclamações posteriores e isso abre espaço pra que as pessoas discutam mais. Vai haver mais abertura e facilidade pra discutir isso com o paciente e com os familiares." (E7) 
Uma pessoa, E2, não soube prever esses efeitos, e outra, E5, apontou que a rotina seria afetada já que o médico terá maior respaldo e segurança para atuar.

\section{Discussão}

Sobre a compreensão dos conceitos de ortotanásia e eutanásia, esperava-se que tais termos fossem bem conhecidos por médicos experientes e qualificados, como os que participaram do presente estudo, e que lidam diuturnamente com questões sobre morte e terminalidade. Os resultados mostraram, de fato, que o conceito de ortotanásia era bem conhecido, pois a literatura revela que a ortotanásia é a morte no tempo correto, sem o uso de esforços abusivos que prolonguem o sofrimento. Os relatos mostraram que os participantes associaram o dar conforto à não-realização de medidas invasivas ou extraordinárias. A ortotanásia seria o não fazer alguma coisa ou 'deixar a vida seguir seu curso', sendo que alguns relatos salientaram que a minimização do sofrimento é uma característica necessária no processo da ortotanásia (Vane, Posso, 2011; Marta, Hanna, Silva, 2010).

Quanto à eutanásia, este conceito também era de conhecimento dos participantes, tendo sido ressaltado que trata-se de uma intervenção ativa, que facilita/agiliza/induz o óbito. Apesar de não ter sido observada no presente estudo, vale destacar que outras pesquisas identificaram confusão conceitual entre esses termos, mas que o de eutanásia é mais conhecido (Vane, Posso, 2011; Vasconcelos, Imamura, Villar, 2011). Essas questões remetem para a importância de estratégias de difusão e de esclarecimentos acerca desses conceitos, partindo de diferentes instituições envolvidas com o tema, incluindo: universidades, conselhos profissionais, entidades científicas e associações de usuários de serviços de saúde.

Quanto às influências no processo de tomada de decisão em relação à introdução ou não de suporte vital, foi possível concluir que critérios técnicos são relevantes para embasar as decisões dos entrevistados, embora vários deles tenham enfatizado razões de ordem relacional e alguns afirmado que motivos subjetivos seriam preponderantes para tais raciocínios. Os relatos chamaram a atenção pela diversidade nesse eixo temático, pois permitiram a identificação de cinco categorias diferentes, indicando que questões de foro íntimo parecem prevalecer. A menção à influência de todos no processo de tomada de decisão merece destaque como uma postura que vai ao encontro de preceitos bioéticos, ao valorizar os atores cruciais nesse processo. Isso porque valorizar de forma contundente o papel da família e do médico, por exemplo, pode levar à infração da autonomia do paciente.

Em sua maioria, os participantes ressaltaram a influência da relação médico-paciente sobre a tomada de decisão no final da vida, destacando, ainda, a relevância da participação da família desde a descoberta da doença, seu tratamento e os momentos finais. De fato, nessa relação, a família deve ser percebida como uma extensão do paciente, ainda mais em contextos de grande vulnerabilidade, quando este não tem condições de decidir e opinar sobre os procedimentos e processos de cuidado. No entanto, a ênfase na anuência familiar parece considerar que ter a família como aliada garante apoio e legitimidade à ação do médico. No entanto, pode-se problematizar que posturas profissionais excessivamente dependentes de atitudes e desejos da família - amplificados por eventuais sentimentos de culpa e medo da perda presentes no contexto familiar - correm o risco de infringir direitos do paciente, e, mesmo, irem de encontro a preceitos éticos que deveriam ser assumidos pelo profissional. Assim, é possível afirmar que ações maleficentes em relação ao paciente podem ter origem na busca incessante da anuência da família.

A iniciativa quanto a conversar sobre limitação ou retirada de suporte vital costuma partir do médico, dadas sua competência e responsabilidade técnicas. Foi enfatizado pelos participantes que se o assunto é discutido ao longo do processo de atenção e cuidado com o paciente e sua família, todos terão, por consequência, a chance de fazer escolhas mais ponderadas e conscientes, calcadas na realidade dos fatos, o que valoriza a importância do diálogo e da comunicação desde o início do tratamento. 
Foi salientado que o diálogo entre os envolvidos - profissionais de saúde, pacientes, familiares deve ser estimulado para que se alcance coesão entre o que se pensa e coerência no modo de agir. Todavia esse dado é o inverso do que a literatura tem indicado (Trigueiro et al., 2010; Souza, Souza, Souza, 2005).

Quase todos os participantes queixaram-se de suas formações, afirmando que a terminalidade e temas correlatos não são abordados de forma suficiente na graduação. Tendo em vista que o curso de medicina se propõe a habilitar profissionais que terão contato com a morte em diferentes momentos de sua prática, defende-se que temas sobre morte, terminalidade, cuidados paliativos e bioética sejam abordados desde a graduação (Siqueira, 2007). Na verdade, as políticas de humanização e educação permanente devem nortear todo esse processo de capacitação, pois esta se dá de modo contínuo no percurso da vida profissional. Os cursos de medicina precisam, por outro lado, prover melhor qualificação desde a graduação, não somente com respeito às questões biomédicas relativas à terminalidade, mas também quanto aos aspectos psicossociais, à comunicação e ao relacionamento com as pessoas que necessitam de atenção e cuidados. Considera-se, assim, a necessidade de se formarem vínculos, fazerem alianças e, assim, buscar a garantia de um tratamento digno até o momento do óbito e do pós-óbito.

Dois terços dos participantes do estudo conheciam a Resolução 1.805/06 do CFM. Outros estudos com objetivos semelhantes encontraram percentuais mais elevados de desconhecimento desse documento (Batista, Seidl, 2011; Vane, Posso, 2011), ainda que tenham sido realizados em período no qual a mesma não estava em vigência.

Cabe destacar ainda que alguns participantes enfatizaram que a Resolução é frágil em termos de suporte jurídico, defendendo a necessidade de uma lei com respaldo do congresso nacional. O retorno da vigência da Resolução é recente, o que reforça a necessidade de sua divulgação e ampla discussão junto à categoria, mediante estratégias diversas, incluindo: a promoção de debates, fóruns e palestras em congressos científicos e eventos da área de saúde, com destaque para os de bioética. Em sua maioria, os participantes consideraram que a regulamentação da ortotanásia não afetará a prática médica atual, uma vez que esse procedimento tem relação com valores pessoais, éticos e morais. Alguns estudos vão ao encontro dessa posição ao destacarem que a ortotanásia já é uma prática comum (Vane, Posso, 2011; Vasconcelos, Imamura, Villar, 2009), independente de regulamentações específicas. Na verdade, segundo um dos entrevistados que discordou dessa posição e opinou afirmativamente pelo impacto da Resolução, este deverá ocorrer, pois o profissional de medicina sentirá mais segurança e respaldo para agir em seu cotidiano diante dessas situações. Recomenda-se que estudos futuros avaliem os efeitos da Resolução na prática profissional de médicos em contextos de terminalidade e processos correlatos.

Pode-se concluir que questões e dilemas relativos ao fim da vida se beneficiam grandemente dos princípios bioéticos. Apesar das críticas à insuficiência do principialismo, percebe-se que este pode respaldar ações humanizadas e éticas no fim da vida. Assim, cabe refletir sobre a justiça contida na utilização da ortotanásia, no sentido de prover, a cada indivíduo, o tratamento mais adequado a sua necessidade. A beneficência representa o fazer o bem e remover o mal, mantendo o paciente sob cuidados na tentativa de minimizar os danos. A não-maleficência, por sua vez, trata de não produzir um mal maior do que o característico da doença, e, por fim, a autonomia que confere ao paciente poder decisório superior ao do médico no tocante a sua própria saúde (Moritz, 2009).

A proposta da ortotanásia não é apressar a morte, mas humanizá-la. Humanização como o lado mais humano do cuidado é recolocar a pessoa no centro do processo, favorecendo a autonomia de suas escolhas, envolvendo, portanto, solidariedade, compaixão, aproximação e respeito (Siqueira, Zoboli, Kipper, 2008). O diálogo deve ser facilitado pelo médico, e não imposto (Deslandes, 2004). Quando o sofrimento de uma doença acomete alguém, é essa pessoa que deveria ter a possibilidade de definir o tipo de tratamento a ser seguido ou não, e, também, o tipo de morte e suas consequências (Braga et al., 2010; Martin, 2010; Pessini, 2007; Schramm, Siqueira-Batista, 2004).

Como limitação do estudo, ainda que o número de participantes tenha sido pequeno, cabe assinalar que essa é uma propriedade de pesquisas qualitativas. De qualquer forma, estudos futuros com número maior de participantes e com uso de metodologias quantitativas poderão aportar outras contribuições ao tema. Uma limitação que se destaca é o fato de os participantes serem apenas de duas 
instituições do DF e provenientes de uma área de atuação: a oncologia. O roteiro de entrevista poderia ter incluído, ainda, uma pergunta referente à aceitação da prática da eutanásia e a percepção sobre sua legalização pelos participantes, considerando sua relevância como tema emergente na bioética.

\section{Colaboradores}

Kilda Mara Sanchez y Sanches idealizou o estudo, responsabilizou-se pela revisão da literatura, coleta e análise de dados, e redação do artigo. Eliane Maria Fleury Seidl foi orientadora do trabalho, auxiliou na análise de dados e na redação final do manuscrito.

\section{Referências}

BARDIN, L. Análise de conteúdo. Lisboa: Edições 70, 2009.

BATISTA, K.T.; SEIDL, E.F.S. Estudo acerca de decisões éticas na terminalidade da vida em unidade de terapia intensiva. Com. Cienc. Saude, v.22, n.1, p.51-60, 2011.

BRAGA, E.M. et al. Cuidados paliativos: a enfermagem e o doente terminal. Investigação, v.10, n.1, p.26-31, 2010.

CONSELHO FEDERAL DE MEDICINA. Resolução 1.805/2006. Dispõe que na fase terminal de enfermidades graves e incuráveis é permitido ao médico limitar ou suspender procedimentos e tratamentos que prolonguem a vida do doente, garantindo-lhe os cuidados necessários para aliviar os sintomas que levam ao sofrimento, na perspectiva de uma assistência integral, respeitada a vontade do paciente ou de seu representante legal. Diário Oficial da União, Brasília, DF, 2006. Seção 1, p.169.

DESLANDES, S.F. Análise do discurso oficial sobre humanização da assistência hospitalar. Cienc. Saude Colet., v.9, n.1, p.7-14, 2004.

GIROND, J.B.R.; WATERKEMPE, R. Sedação, eutanásia e o processo de morrer do paciente com câncer em cuidados paliativos: compreendendo conceitos e interrelações. Cogitare Enferm., v.11, n.3, p.258-63, 2006.

GRACIA, D. Ética de los confines de la vida. Colômbia: Editorial El Búho, 1999. MARINO JÚNIOR, R. Em busca de uma bioética global. São Paulo: Hagnos, 2009. MARTA, G.N.; HANNA, A.S.; SILVA, J.L.F. Cuidados paliativos e ortotanásia. Diagn. Trat., v.5, n.2, p.58-60, 2010.

MARTIN, B. Techniques to pass on technology and euthanasia. Bol. Sci. Technol Soc., v.30, n.1, p.54-9, 2010.

MENEZES, M.B.; SELLI, L.; ALVES, J.S. Distanásia: percepção dos profissionais da enfermagem. Rev. Latinoam. Enferm., v.17, n.4, p.443-8, 2009.

MIGLIORE, A.D.B. et al. Dignidade da vida humana. São Paulo: LTR, 2010.

MORITZ, R.D. A equidade e a não maleficência no cuidado de pacientes críticos terminais. Rev. Bras. Ter. Intensiva, v.21, n.4, p.341-2, 2009.

PELIZZOLI, M. Bioética como um novo paradigma. Rio de Janeiro: Vozes, 2007.

PESSINI, L. Distanásia: até quando prolongar a vida? São Paulo: Edições Loyola, 2007.

. Eutanásia: por que abreviar a vida? São Paulo: Centro Universitário São

Camilo, 2004. 
PESSINI, L.; BERTACHINI, L. Humanização e cuidados paliativos. São Paulo: Loyola, 2004.

REIRIZ, A.B. et al. Cuidados paliativos, a terceira via entre eutanásia e distanásia: ortotanásia. Prat. Hosp., v.6, n.48, p.77-82, 2006.

SANCHEZ Y SANCHES, K.M. Ortotanásia: uma decisão frente à terminalidade. 2012. Dissertação (Mestrado) - Cátedra Unesco de Bioética, Faculdade de Ciências da Saúde da Universidade de Brasília, Brasília. 2012.

SCHRAMM, F.R.; SIQUEIRA-BATISTA, R. Eutanásia: pelas veredas da morte e da autonomia. Cienc. Saude Colet., v.9, n.1, p.31-41, 2004.

SILVA, R.C.F.; HORTALE, V.A. Cuidados paliativos oncológicos: elementos para o debate de diretrizes nesta área. Cad. Saude Publica, v.22, n.10, p.2055-66, 2006.

SIQUEIRA, J.E. Educação médica em bioética. Rev. Bras. Bioet., v.3, n.3, p.301-27, 2007.

SIQUEIRA, J.E.; ZOBOLI, E.; KIPPER, D.J. Bioética clínica. São Paulo: Gaia, 2008.

SOUZA, L.B.; SOUZA, A.M.A.; SOUZA, L.E.E.M. A ética no cuidado durante o processo de morrer: relato de experiência. Rev. Bras. Enferm., v.58, n.6, p.731-4, 2005.

TRIGEIRO, T.H. et al. Dilemas éticos vividos pelos enfermeiros diante da ordem de não reanimação. Cienc. Cuid. Saude, v.9, n.4, p.721-7, 2010.

URBAN, C.A. et al. Eutanásia, suicídio assistido e cuidados na fase terminal da vida na visão de médicos oncologistas. RUBS, v.1, n.2, p.72-8, 2008.

VANE, M.F.; POSSO, I.P. Opinião dos médicos das Unidades de Terapia Intensiva do Complexo Hospital das Clínicas sobre a ortotanásia. Rev. Dor, v.12, n.1, p.39-45, 2011.

VASCONCELOS, T.J.Q.; IMAMURA, N.R.; VILLAR, H.C.E.C. O impacto da resolução CFM 1.805/06 sobre os médicos que lidam com a morte. Rev. Bioet., v.19, n.2, p.501-22, 2011.

SANCHEZ Y SANCHES, K.M.; SEIDL, E.M.F. Ortotanasia: una decisión frente a la terminación. Interface - Comunic., Saude, Educ., v.17, n.44, p.23-34, jan./mar. 2013.

La ortotanasia está regulada en Brasil a través de la Resolución 1805/2006. Esta investigación tiene como objetivo reflexionar y debatir sobre las medidas de limitación o retirada del soporte vital en situaciones terminales. Participaron diez médicos oncólogos de servicios públicos de salud del Distrito Federal, Brasil. Un guía de entrevista semi-estructurada orientó la investigación. Los datos se analizaron mediante el análisis del contenido. Casi todos los participantes tenían una concepción de la ortotanasia y la eutanasia en consonancia con la literatura. Siete médicos conocían la resolución del CFM y tres mencionaron la debilidad legal de una reglamentación proveniente de una entidad de clase. Ocho médicos dijeron que esta reglamentación no afectará en gran medida la práctica diaria. Principios de la bioética pueden contribuir al esclarecimiento de los dilemas sobre la retirada o la limitación del soporte vital.

Palabras clave: Muerte. Terminalidad. Ortotanasia. Soporte vital. Bioética. Prevación de tratamiento. 